\title{
Evolution of Elephants and Suids in Eust Africa
}

RECENT and ongoing excavations at Pleistocene and earlier sites along the eastern shores of Lake Rudolf in northern Kenya by Richard Leakey and his colleagues have yielded more early hominids than found at any other fossil locality in east Africa (R. E. F. Leakey, Nature, 231, 241 ; 1971 and 237, 246 ; 1972). As the collections increased it became apparent that here were the remains of two types of hominid. A robust australopithecine, reminiscent of some found at Olduvai Gorge, Tanzania, appears to have lived alongside a much more advanced hominid, although it presumably occupied another ecological niche.

To establish that more than one hominid type coexisted for any length of time-long enough to evolve as distinct groups - demands accurate mapping and relative dating of the horizons in which the hominids are found. It is only in east Africa that there is enough fossil evidence to lend possible support to this model. For not only is there a sufficiency of early hominids of more than one kind but they occur at more than one site, at more than one time horizon and associated with the remains of an abundant mammal fauna. The discovery of these early hominids has focused attention on the problem of Plio-Pleistocene correlation and on the necessity for establishing evolutionary sequences for hominids and other vertebrates.

Traditionally, the rare occurrences of early hominids in Pleistocene deposits have been dated, relatively, from the fauna found associated with them. Special attention was paid to new and rapidly evolving forms, such as the elephant. At one time all the European early hominids had been dated in this way. It was realized, however, that long-range correlations, as between continents, were not advisable. Differential rates of migration and climatic factors had too great an influence on the faunas. With improved collecting techniques it became apparent that faunal barriers exist even regionally and can affect the distribution of animals in nearby sites. This growing awareness of the obvious errors in attempting correlations based on similar faunal assemblages has latterly made stratigraphers at best dubious of such a dating method.

Many palaeontologists, including the palaeoanthropologists, turned to the more absolute methods of dating, in particular to potassium-argon radiometric sampling. This has been of immense importance in establishing sequences at, for example, Olduvai Gorge. Similarly, dating of volcanic tuffs in progress at the East Rudolf sites will, it is hoped, provide an absolute chronology for the area. Already the dating of one tuff (KBS) to $2.6 \mathrm{~m} . \mathrm{y}$. indicates that the deposits are very early Pleistocene in age and extend into the Pliocene. Radiometric techniques can usually be applied reliably only to primary volcanic rocks, which themselves seldom contain fossils. Thus radiometric dates from a sequence of basalts or tuffs offer a series of bracketing dates for the intervening sediments and their included fossils. These intervening deposits can represent a very long time during which there can be considerable changes in the fauna of the region, both through in situ evolution and migration. For some time there has been a need for a means of filling out and "calibrating" the radiometric dates; that is, a means of checking their reliability against other dating criteria.

Elephants and suids were among the mammalian groups which during Plio-Pleistocene times were increasing in number and diversity. By meticulous sampling, Maglio (see page 379) has been able to establish trends in the evolution of elephants and suids at East Rudolf based on changes in tooth size. Both the suid and elephant trends show an increase in size and hypsodonty (height) of the molars although the crania remain remarkably constant. These animals are particularly suitable for this technique ; their teeth are distinctive and often preserved because of their size and thick enamel. In the elephant three lineages can be traced from mid, or late, Pliocene origins into the Pleistocene, and it is apparent that more than one species coexisted at East Rudolf.

Another rapidly evolving group, that of the suid Mesochoerus limnetes, offers a further means of faunal correlation, for the teeth are separable into three size morphs, associated with the three lithological members of the East Rudolf formations. Whether these represent three grades in a lineage or three ecological types further reflected in the different lithologies is irrelevant. To date, they offer the best means of relative correlation at East Rudolf.

Maglio's earlier attempts to correlate between sites are replaced here by a more cautious attitude. It seems that sequences should be established for a given area before attempting longer-range correlation with sequences elsewhere. Although the same species of Mesochoerus limnetes is known to occur in the Shungura Formation of the lower Omo Valley to the north of Lake Rudolf and at Olduvai Gorge to the south, Maglio recognizes that at this stage it is more meaningful to restrict comparison to material from the Rudolf area alone. Such correlations as he does attempt are of little value because the method is a long way from being empirical.

Whether hominids, always comparatively rare, were evolving rapidly at this time is impossible to say until more have been found. It seems from published mandible size measurements of the highly variable australopithecines at Koobi Fora and Ileret (R. E. F. Leakey, Nature, 237, 246 ; 1972) that they hardly show any such trend. Maglio stresses that as a relative dating technique this method is dependent upon the establishment of trends detected in faunal assemblages. Single teeth, or small samples, can be very misleading.

Now that the idea of diversity among the hominids is becoming generally accepted, it is difficult to understand quite why the single species concept for human evolution hung on for so long among palaeoanthropologists. Man is unique in many respects but in his evolution is likely to have followed the pattern of many other groups ; that of diversification, adapting to the available ecological niches. That he did this, not once but many times, seems equally probable. Each time the more successful have survived while, with competition and changing conditions, the less adaptable gave up the struggle.-From a Correspondent. 